\title{
CORE NETWORK EPC REDIMENSIONING 4G LTE DI WILAYAH REGIONAL SULAWESI
}

\author{
Vika Oktavia $^{1}$, Nachwan Mufti Adriansyah ${ }^{2}$, Hafidudin $^{3}$ \\ ${ }^{1,2}$ Fakultas Teknik Elektro, Universitas Telkom \\ ${ }^{3}$ Fakultas Ilmu Terapan, Universitas Telkom \\ 1vikaoktavia@students.telkomuniversity.ac.id, ${ }^{2}$ nachwanma@telkomuniversity.ac.id, \\ hafidudin@telkomuniversity.ac.id
}

\begin{abstract}
Abstrak
Core network dibutuhkan sebagai penyedia content layanan kepada user. Proses dimenssioning core network 4G LTE di wilayah regional Sulawesi dengan melakukan studi kasus di PT. Telekomunikasi Selular (Telkomsel) hingga tahun 2022. Pada jaringan 4G LTE dengan CSFB diperlukan minimum elemen jaringan 9 MSS, 2 HSS, 5 S/PGW, dan 5 MME. Untuk dimensioning interface dapat mengetahui bandwidth minimum yang harus disediakan. Interface control plane terdiri dari S6a, S11, S10, S1-MME, S5/S8 memerlukan 0,4015 Gbps dan kebutuhan bandwidth interface user plane terdiri dari S5/S8 user plane, S1-U dan SGi adalah 20,075 Gbps. Dari hasil dimensioning element dan interface jaringan menghasilkan topologi jaringan EPC yang dapat diimplementasisan di wilayah regional Sulawesi. Untuk membentuk sistem yang handal dari segi teknikal dan biaya dengan topologi full connection mesh menggunakan pooling sistem. Penentuan link transport dari EPC menghasilkan dua skenario topologi planning core. Sehingga, infrastruktur topologi tersebut dapat menguntungkan baik dari sisi pelanggan maupun operator. Sehingga untuk biaya infrastruktur core network berbanding dengan efisiensi bandwidth yang disediakan dengan memilih rekomendasi link transport untuk skenario yang kedua.
\end{abstract}

Kata Kunci: 4G LTE,CSFB, EPC, core network, network planning

\section{Abstract}

Core network is required as a service content provider to the user. The designing of a core network or 4G LTE core network in the Sulawesi Region will be done by conducting a case study at PT. Telekomunikasi Selular (Telkomsel) until year 2022. 4G LTE network with CSFB requires minimum network element 9 MSS, 2 HSS, $5 \mathrm{~S}$ / PGW, and 5 MME. For dimensioning interface can know the minimum bandwidth that must be provided. The control plane interface consisting of S6a, S11, S10, S1-MME, S5 / S8 requires 0.4015 Gbps and the user plane bandwidth requirement bandwidth consisting of S5 / S8 user plane, S1-U and SGi is 20.075 Gbps. From the results of dimensioning elements and network interfaces to produce EPC network topology that can be implemented in region of Sulawesi. To establish a reliable system in terms of technical and cost with a full connection mesh topology using pooling system. Determination of transport links from EPC generates some topology planning core scenarios. For the topology infrastructure is profitable from the customer and operator side. So, for core network infrastructure costs are proportional to the bandwidth efficiency provided by selecting transport link recommendations for the second scenario.

Keywords: 4G LTE, CSFB, EPC, core network, network planning

\section{Pendahuluan}

Perkembangan teknologi seluler yang berkembang sangat pesat disebabkan oleh adanya kebutuhan kapasitas yang semakin besar, efesiensi spektrum yang semakin tinggi dan kemampuan dalam memberikan layanan data maupun suara dengan data rate yang lebih tinggi. Untuk memenuhi kebutuhan tersebut bagi operator yang menggunakan teknologi GSM, dengan beralih ke teknologi 4G LTE. Long Time
Evolution (LTE) diciptakan untuk memperbaiki teknologi sebelumnya. Peralihan dari GSM ke 4G LTE memerlukan perencanaan yang baik dan matang dalam memperoleh sistem yang handal [1]. Untuk mengatasi peningkatan pelanggan sebesar $2,435 \%$ permintaan akan kebutuhan komunikasi layanan suara Thirdgeneration partnership project-long term evolution (3GPP-LTE) merupakan salah satu standar dari sistem wireless next-generation yang diaplikasikan untuk dapat memenuhi kebutuhan pelanggan akan layanan 
yang terus meningkat untuk beberapa tahun kedepannya. 3GPP Long Term Evolution (LTE) di pasarkan dengan dengan nama 4G LTE terdiri dari 3 bagian utama yaitu User Equipment (UE), Evolved Packet Core Network (EPC), dan UMTS Terrestial Radio Access Network (E-UTRAN). Jaringan inti pada 4G LTE hanya mempunyai paket Switched domain,untuk mendukung layanan suara untuk itu digunakan CS Fallback [1]. Perancangan jaringan inti untuk penelitian sebelumnya dilakukan pada pada area cakupan kota Bandung dan hasil yang didapatkan elemen jaringan yang sesuai dengan standar operator, dengan persebaran trafik bersifat merata [2]. Dengan adanya penelitian ini dapat mengetahui proses perencanaan pada jaringan inti $4 \mathrm{G}$ yaitu EPC (Evolved Packet Core) dengan cakupan wilayah yang lebih luas yaitu regional pulau Sulawesi. Menghasilkan beberapa skenario topologi jaringan EPC sehingga mengoptimalkan hasil perancangan core network $4 \mathrm{G}$ LTE untuk wilayah cakupan yang lebih luas.

\section{Tinjauan Pustaka}

\subsection{Evolved Packet Core (EPC)}

3GPP membuat dan menstandarisasi EPC yaitu 3GPP TS 23.401 v8.0.0. Keunggulan dari EPC selain jaringan yang All-IP memiliki arsitektur yang sederhana dengan kecepatan transfer data yang tinggi. Interworking terhadap legacy system seperti GSM, CDMA, PSTN, UMTS dan sebagainya. EPC mendukung segala jaringan akses dengan paket apapun seperti Wifi dan WiMAX. Untuk layanan multimedia dan real-time memiliki QoE (Quality of Experience) yang baik, selain itu EPC mendukung mobilitas dengan roaming lebih baik dari generasi sebelumnya [2]. EPC merupakan salah satu bagian utama pada teknologi LTE yang memiliki konsep arsitektur yaitu menggunakan protocol IP yang berbasis paket yang disebut sebagai All-IP (AllInternet Ptotocol). EPC terdiri dari elemen jaringan utama dan interface yang menghubungkan tiap komponen utama dapat dilihat pada Gambar 1.

Pada penelitian ini dilakukan proses dimensioning jaringan yaitu pencarian jumlah kebutuhan elemen jaringan sebagai komponen utama dan interface yang menghubungkan tiap elemen, untuk keperluan beberapa tahun kedepan.

\subsection{CSFB (Circuit Switch Fallback) pada EPC}

CSFB distandarisasi oleh 3GPP yaitu 23.272 [2], menjadi solusi bagi para operator sampai jaringan IP multimedia siap untuk digunakan. Operator seluler menggunakan jaringan 4G LTE tanpa mengesampingkan jaringan $2 \mathrm{G}$ atau $3 \mathrm{G}$ yang telah ada. Dengan adanya CSFB sehingga UE (User Equipment) melakukan drop koneksi ke jaringan $2 \mathrm{G}$ atau 3G. Salah satu karakteristik EPC adalah mendukung adanya teknologi seluler dengan metode CSFB, untuk arsitektur dari CSFB pada (Gambar 2).

Pada jaringan 3G domail CS (Circuit switch) terhubung ke VLR (Visited Location Register) dan MSC (Mobile Switching Center). SGSN (Serving GPRS Support Node) terhubung ke S/PGW (Serving Packet Gateway) dan MME. CSFB juga memfasilitasi mobility management pada 3G CS domain dan EPC. Dalam CSFB melakukan transfer call request dari CS domain ke LTE melalui SGs interface. SGs adalah interface yang berfungsi menghubungkan element network MME (Mobability Management Entity) dengan MSC server di core network 3G.

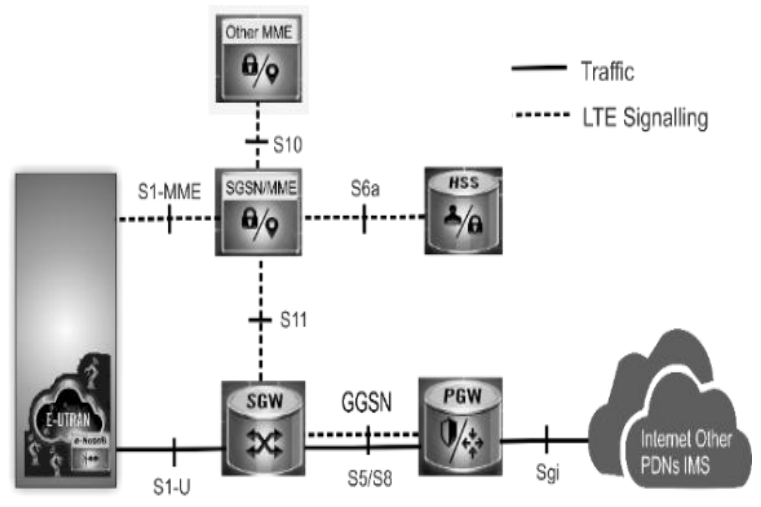

Gambar 1. Core network EPC [2]

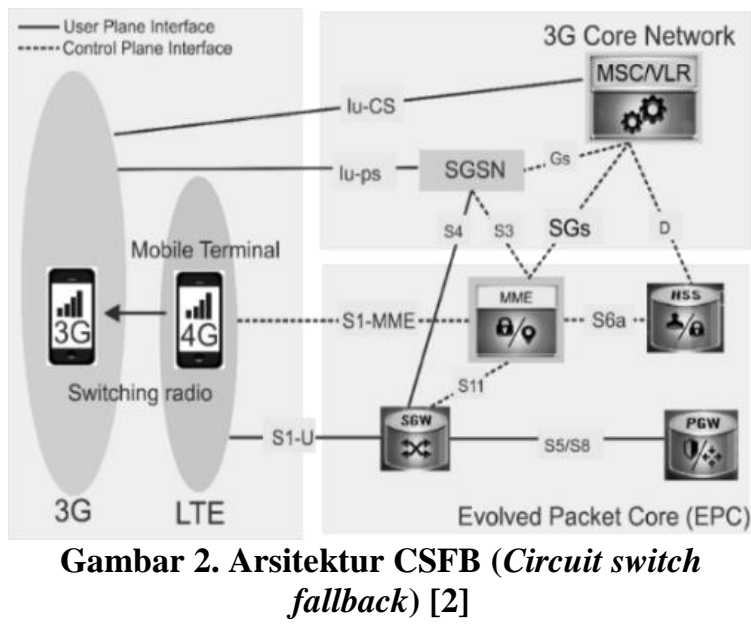

\subsection{Forecasting Subscribers. [4]}

Jumlah pelanggan menjadi parameter yang sangat penting dalam proses dimensioning element jaringan core network. Pada penelitian proses forecasting jumlah pelanggan hingga tahun ke-n. Dilakukan dengan persamaan aritmatika untuk 
mendapatkan tingkat pertumbuhan pelanggan setiap tahunnya dengan persamaan

$$
P t=P o(1+R)^{n}
$$

$P o=$ Subscriber tahun dasar.

$P t=$ Subscriber tahun $t$.

$R=$ Rasio pertumbuhan subscriber

Dimana

$$
R=\left(n \sqrt{\frac{P t}{P o}}-1\right)
$$

\subsection{Proses Dimensioning Element Core Network EPC}

Pada penelitian yang dilakukan dengan proses dimensioning pencarian jumlah kebutuhan element jaringan pada EPC akan dijelaskan sebagai berikut.

\subsubsection{Mobile Soft Switch (MSS)}

MSS juga dapat disebut Mobile Switching Server pada 3G yaitu MSC server memiliki fungsi sebagai controlling pada MGW maupun call control. MSS berfungsi dalam melayani drop call [5]. Proses dimensioning MSS dipengaruhi oleh simultaneous call processing dan BHCH (Busy Hour Call Attempt) [6].

$$
\mathrm{MSS}=\operatorname{Max}\left[\begin{array}{l}
\frac{\text { Jumlah subs }}{\text { Sub_cap }}, \\
\frac{\text { BHCA }}{\text { BHCA_Cap }} \\
\frac{\text { Simult_Call }}{\text { SimultCall_Cap }}
\end{array}\right]
$$

$$
\begin{aligned}
& \text { Jumlah MSS = Dimensioning kebutuhan } \\
& \text { MSS hingga tahun ke- } n \text {. } \\
& \text { Jumlah Subs = Jumlah pelanggan hingga } \\
& \text { tahun akhir perencanaan. } \\
& \text { Sub_cap } \quad=\text { Kapasitas Pelanggan MSS. } \\
& \text { BHCA }=\text { Busy Hour Call Attempt. } \\
& \text { BHCA_Cap = Kapasitas BHCA element } \\
& \text { jaringan MSS. } \\
& \text { Simult_Call = Jumlah panggilan yang } \\
& \text { terjadi secara bersamaan. } \\
& \text { SimultCall_Cap = Kapasitas Simultaneous Call } \\
& \text { Processing }
\end{aligned}
$$

\subsubsection{Mobability Management Entity (MME)}

MEE melakukan komunikasi dengan HSS untuk penentuan drop call layanan $4 \mathrm{G}$ ke $3 \mathrm{G}$. Pada penggunaan teknologi dengan metode CS Fallback MME adalah SGSN pada jaringan 4G LTE. Untuk fungsi session pada MME di non aktifkan hanya mobility management. SGSN pada jaringan $4 \mathrm{G}$ untuk mobility management, sehingga MME merupakan SGSN pada jaringan 4G LTE. Fungsi utama dari perangkat jaringan MME yaitu bearer management untuk release, estabilishment dan maintenance bearer. Selain itu connection management MME dapat membuat dan mengamankan jaringan [7]. Proses dimensioning MME dapat dilakukan berdasarkan jumlah subscriber yang attach secara simultan, data throughput dan simultaneous bearer/PDP context. Kebutuhan jumlah MME dapat dicari dengan menggunakan persamaan sebagai berikut [8].

$$
M M E=M A X\left[\begin{array}{l}
\frac{\text { Jumlah sub }}{\text { Sub cap }}, \\
\frac{\text { Bearer }}{\text { bearer cap }}, \\
\frac{\text { Trafik }}{\text { Throughput Cap }}
\end{array}\right]
$$

$$
\begin{aligned}
& \text { Jumlah sub } \quad=\quad \text { Jumlah pelanggan pada jam } \\
& \text { sibuk }(60 \% \text { pelanggan } \\
& \text { eksisting). } \\
& \text { Sub cap } \quad=\text { Kapasitas Pelanggan MME. } \\
& \text { Bearer } \quad=\text { Menyatakan banyaknya } \\
& \text { pelanggan yang attach pada } \\
& \text { MME. } \\
& \text { bearer cap }=\text { Kapasitas perangkat pada } \\
& \text { MME. } \\
& \text { Trafik = Data trafik eksisting kondisi } \\
& \text { MME (Mbps). } \\
& \text { Throughput Cap = Kapasitas trafik pada } \\
& \text { perangkat MME (Mbps). }
\end{aligned}
$$

\subsubsection{Home Subcriber Server (HSS)}

HSS pada jaringan 4G LTE fungsinya sama dengan HLR (Home Location Register) pada jaringan 3G.HSS menjadi tempat penyimpanan data pelanggan untuk semua data permanen pengguna (user). Fungsi utama HSS yaitu AAA (Authentication, Acounting dan Authorization). Jumlah HLR berdasarkan jumlah subscriber dari hasil forecasting dan kapasitas HLR. Dalam mencari jumlah elemen HSS yang dibutuhkan jaringan inti dapat menggunakan persamaan [6].

$$
\text { Dimensioning HSS }=\frac{\sum \text { Subcriber }}{\text { HSS Capacity }}
$$

$\begin{aligned} \text { Dimensioning HSS }= & \begin{array}{l}\text { Dimensioning kebutuhan } \\ \text { HSS hingga tahun ke- } n .\end{array} \\ \sum \text { Subcriber }= & \begin{array}{l}\text { Jumlah pelanggan hingga } \\ \text { tahun akhir perencanaan. }\end{array} \\ = & \begin{array}{l}\text { Kapasitas Pelanggan HSS } \\ \\ \text { HSS Capacity } 90 \% \text { Utility eksisting } \\ \text { pelanggan })\end{array}\end{aligned}$




\subsubsection{Serving/Packet Data Gateway (S/PGW)}

S-PGW memiliki fungsi yang sama dengan GGSN (Gateway GPRS Support Node) pada 4G LTE yaitu sebagai elemen gateway yang berhubungan dengan jaringan luar. Sebagai jembatan antara switching user plane dan manajemen yang berfungsi sebagai pengontrolan [9]. Pada generasi ke-empat teknologi 4G LTE Fungsi session yang tidak di aktifkan pada MME dialihkan ke GGSN. S-PGW dapat dicari jumlah kebutuhan untuk beberapa tahun kedepan berdasarkan trafik dan simultaneous bearer context. Pencarian jumlah kebutuhan dengan menggunakan persamaan

$$
\mathrm{S} / \mathrm{PGW}=\operatorname{Max}\left[\begin{array}{l}
\frac{\text { Bearer }}{\text { bearer cap }} \\
\frac{\text { Trafik }}{\text { Throughput Cap }}
\end{array}\right]
$$

$$
\begin{array}{ll}
\text { Bearer } & =\begin{array}{l}
\text { Banyaknya pelanggan yang } \\
\text { attach pada S/PGW. }
\end{array} \\
\text { bearer cap } & =\text { Kapasitas perangkat S/PGW. } \\
\text { Trafik } & =\begin{array}{l}
\text { Data trafik eksisting kondisi } \\
\text { S/PGW (Mbps). }
\end{array} \\
\text { Throughput Cap }= & \text { Kapasitas trafik pada } \\
& \text { perangkat S/PGW (Mbps). }
\end{array}
$$

\subsubsection{Interface Core Network.}

Interface core network merupakan node yang menghubungkan dan melakukan koneksi pertukaran data tiap elemen-elemen jaringan pada core network. Kebutuhan jumlah minimum bandwidth yang harus di sediakan tiap link dapat diketahui melalui proses dimensioning interface. Interface pada EPC terdiri dari interface S1-U, Sgi, dan S5/S8 yang merupakan interface user plane yang membawa data trafik yang berhubungan dengan user. Sehingga membutuhkan bandwidth yang lebih besar dibandingkan dengan interface S10, S11, S5/S8, S1 MME dan S6a adalah interface control plane yang menghubungkan tiap elemen jaringan sebagai interface signaling.

- Bandwidth Control Plane jml subcriber $\times$ Sig msg per sub Busy Hour

$$
3600
$$

- Bandwidth User Plane

$$
\frac{\text { jml subcriber×packet per sub Busy Hour }}{3600}
$$

Jumlah subscriber $=$ Jumlah Subcriber hasil forecasting

Packet per sub Busy Hour = Jumlah packet per subcriber pada saat jam sibuk

Signalling msg per sub $\mathrm{BH}=$ Jumlah subcriber pada jam sibuk (byte)

\section{Kondisi Eksisting Jaringan dan Forecasting Subscribers}

\subsection{Alur Perencanaan}

Proses tahapan diagram tersebut Gambar 3 yaitu perencanaan awal dikakukan survei data lapangan sesuai dengan lokasi perancangan untuk penelitian ini dilakukan di PT Telekomunikasi Seluler untuk wilayah regional Sulawesi. Survey data lapangan dengan mencari jumlah pelanggan dan jumlah penduduk. Jumlah pelanggan dan penduduk merupakan parameter yang sangat dibutuhkan dalam perencanaan core network. Karena setiap subscriber memiliki profil yang berbeda-beda dalam membangkitkan trafik. Pada penelitian ini, data yang digunakan adalah jumlah subcriber VLR operator Telkomsel dari tahun 2014 hingga 2017. Proses selanjutnya setelah data didapatkan dapat dilakukan prediksi jumlah pelanggan untuk beberapa tahun kedepan. Pada penelitian ini yang digunakan prediksi jumlah penduduk untuk 5 tahun ke depannya, hingga tahun 2022. Perancangan jaringan inti tidak hanya dilakukan untuk melayani semua pelanggan yang ada pada saat ini, tetapi juga untuk melayani pelanggan hingga beberapa tahun kedepannya. Untuk itu diperlukan peramalan jumlah pelanggan untuk beberapa tahun kedepannya.
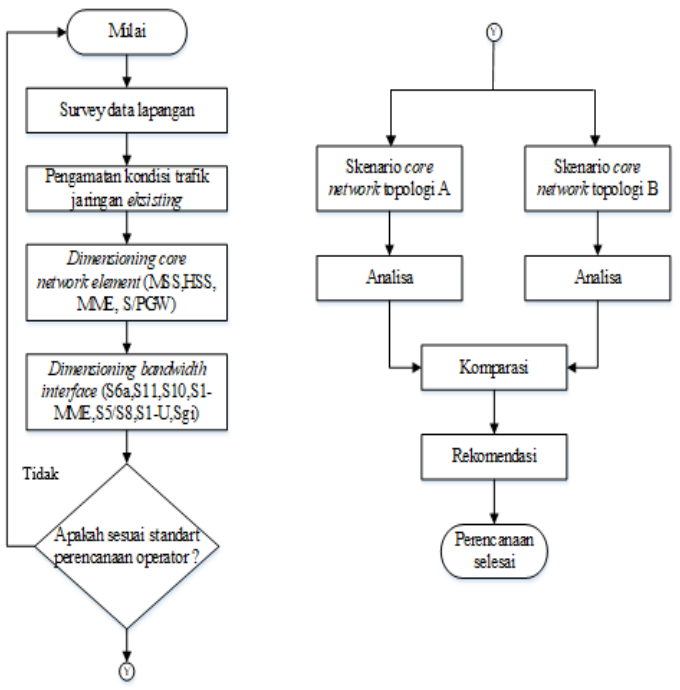

Gambar 3. Diagram alir perancangan core network 4G LTE

\subsection{Kondisi Eksisting Jaringan Telkomsel di Wilayah Regional Sulawesi}

Dalam melakukan dimensioning network element dan interface 4G LTE, dijadikan standarisasi dalam melakukan proses dimensioning. Kondisi eksisting elemen core network dan terdiri dari 
1) 8 MSC server atau MSS

2) 4 MME (SGSN) yaitu MME yaitu ujung pandang 5, MME ujung pandang 6, MME Manado 1, MME Manado 2.

3) $4 \mathrm{~S} / \mathrm{PGW}$ atau GGSN yaitu S/PGW ujung pandang 1, S/PGW ujung pandang 2, S/PGW Sudiang 1, S/PGW sudiang 2.

4) 2 HSS yaitu di Makassar dan Manado

\subsection{Forecasting Jumlah Subscribers pada Operator Telkomsel}

Untuk forecasting pelanggan dapat dicari dengan penggunaan persamaan pertumbuhan jumlah subscriber telah dilampirkan pada Persamaan

$$
\begin{aligned}
& P t=P o(1+R)^{n} \\
P o= & \begin{array}{l}
\text { Subscriber tahun dasar } \\
11.923 .301
\end{array} \\
P t= & \text { Subscriber tahun t 12.815.668 } \\
R \quad= & \text { Rasio peningkatan (variabel } \\
\text { yang di cari dalam } & \text { perhitungan) } \\
n \quad= & 3 \text { (Tahun 2014 hingga 2017) }
\end{aligned}
$$

Untuk mencari persentasi jumlah pertumbuhan pelanggan atau rasio peningkatannya dengan menggunakan persamaan tersebut

$$
\begin{array}{ll}
\mathrm{Pt} & =\mathrm{P}_{o}(1+\mathrm{R})^{\mathrm{n}} \\
12.815 .668 & =11.923 .301(1+\mathrm{R})^{3} \\
1,074842277 & =(1+\mathrm{R})^{3} \\
1,024349705 & =1+\mathrm{R} \\
\mathrm{R} & =1,024349705-1 \\
\mathrm{R} & =0,024349705 \\
\mathrm{R} & =2,435 \%
\end{array}
$$

Dari persamaan tersebut diperoleh nilai jumlah pertumbuhan pelanggan atau rasio peningkatan pelanggan rata-rata $(R)$ sebesar $2,435 \%$. Sehingga dari data pelanggan dari tahun 2014 hingga 2017 diperoleh peningkatan jumlah pelanggan operator Telkomsel sebesar 2,435\% per tahun.Untuk itu pada tahun akhir perencanaan yaitu pada tahun 2022 dapat diprediksikan operator Telkomsel memiliki jumlah pelanggan untuk wilayah regional Sulawesi. Dengan menggunakan rasio peningkatan forecasting subscriber dapat dilakukan dengan di asumsikan tiap tahunnya meningkat sebesar 2,435\% sehingga dapat di peroleh pada tahun 2022 Operator Telkomsel yang menggunakan layanan 4G LTE sebesar 14.453.835. Prediksi jumlah subscriber operator Telkomsel dengan peningkatan 2,435\% dapat dilihat pada Tabel 1.

\section{Core Network Planning dan Analisis}

\subsection{Hasil Dimensioning.}

Pada Tabel 2 tahun 2017 kondisi eksisting elemen jaringan dan standart yang dimiliki operator Telkomsel pada saat ini memiliki 8 MSC server, 4 MME, 4 S/PGW, dan 2 HSS. Akan dianalisa dengan standar yang dimiliki sebagai standart minimal dari hasil perhitungan jumlah elemen jaringan dan bandwidth interface yang didapatkan hingga akhir tahun perencanaan yaitu 2022. Hasil dimensioning interface Tabel 3 diperoleh untuk kapasitas jumlah subscriber yang telah di prediksikan sampai tahun 2022 sebesar 14.453 .838 dengan rasio peningkatan pelanggan setiap tahunnya $2,435 \%$.

\section{Tabel 1. Forecasting subscribers sampai tahun} 2022

\begin{tabular}{|l|c|}
\hline Tahun & Jumlah Subscribers \\
\hline 2014 & 11.923 .301 \\
\hline 2015 & 12.510 .799 \\
\hline 2016 & 12.647 .335 \\
\hline 2017 & 12.815 .668 \\
\hline 2018 & 13.127 .730 \\
\hline 2019 & 13.447 .391 \\
\hline 2020 & 13.774 .835 \\
\hline 2021 & 14.110 .253 \\
\hline 2022 & 14.453 .838 \\
\hline
\end{tabular}

Tabel 2. Hasil dimensioning elemen jaringan

\begin{tabular}{|l|l|}
\hline Network Element & Jumlah Hasil Dimensioning \\
\hline MSS (MSC Server) & 9 buah \\
\hline HSS & 2 buah \\
\hline MME & 5 buah (active dan standby) \\
\hline S/PGW & 5 buah (active dan standby) \\
\hline
\end{tabular}

Tabel 3. Hasil dimensioning Interface EPC

\begin{tabular}{|l|l|}
\hline Interface & Bandwidth \\
\hline S6a & 0,4015 Gbps \\
\hline S11 & $0,4015 \mathrm{Gbps}$ \\
\hline S10 & $0,4015 \mathrm{Gbps}$ \\
\hline S5/S8 user plane & 20,075 Gbps. \\
\hline S5/S8 control plane & 0,4015 Gbps \\
\hline S1-U & 20,075 Gbps. \\
\hline S1-MME & 0,4015 Gbps \\
\hline Sgi & 20,075 Gbps. \\
\hline SGs & 0,4015 Gbps \\
\hline
\end{tabular}




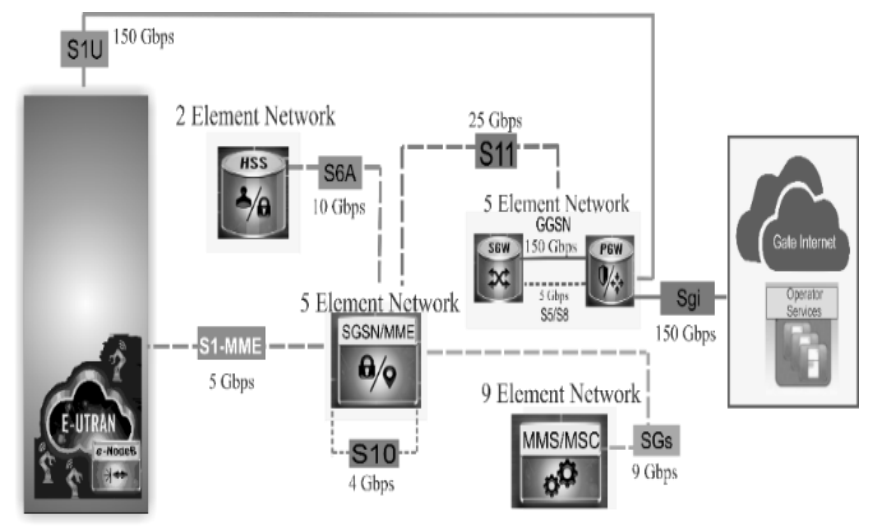

Gambar 4. Topologi planning core EPC skenario 2

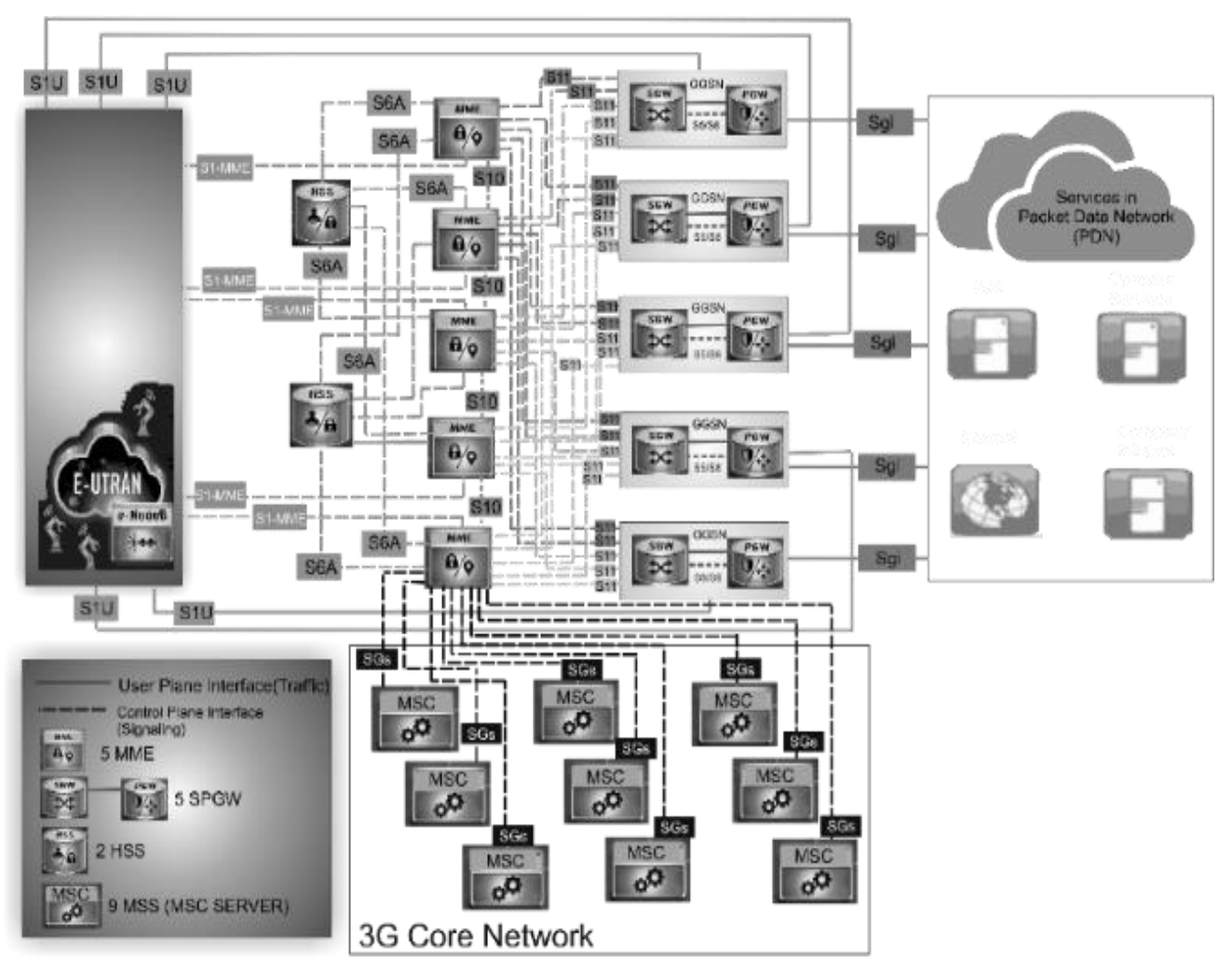

Gambar 5. Pemodelan hasil dimensioning topologi EPC jaringan 4G LTE

\subsection{Perbandingan Topologi Planning Core}

Pada kedua skenario topologi planning core EPC memiliki kelebihan dan kekurangan masing-masing dari model topologi yang di tawarkan dengan menggunakan aturan kondisi real yang ada di lapangan. Topologi planning core EPC skenario 1 memiliki kelebihan system routing lebih mudah dibandingkan menggunakan topologi pada skenario 2 . Karena kebutuhan kabel optik lebih sedikit sehingga konfigurasi routing dapat dilakukan dengan mudah.
Bandwidth total yang disediakan lebih besar menguntungkan dari pihak operator dan jaminan service layanan yang tinggi di berikan ke pelanggan. Kekurangan yang dimiliki adalah system yang belum handal.

Topologi planning core EPC untuk skenario yang kedua memiliki kelebihan yaitu bandwidth yang di sediakan lebih efisien. Karena masih menguntungkan dari pihak operator salain itu dari cost yang dikeluarkan lebih kecil dibandingkan skenario yang pertama. Kehandalan sistem yang lebih tinggi dengan 
menggunakan pooling sistem, Jika terjadi gangguan pada core network perangkat element core yang lain dengan fungsi yang sama dapat mengatasi dan menghendel sementara gangguan tersebut. Jika salah satu link terputus atau down karena trafik penuh maka tidak mempengaruhi sistem yang lain. Karena kabel yang digunakan untuk satu link dipakai untuk satu perangkat. Kekurangannya membutuhkan banyak kabel optik yaitu 15 kabel interface user plane dan 58 kabel interface control plane. Sehingga memiliki konfigurasi proses routing yang sulit. Untuk perbandingan skenario topologi planning core berdasarkan link transport. Perbedaan yang signifikan dari kebutuhan kabel link interface user plane dan control plane.

\subsection{Rekomendasi untuk Implementasi dari Hasil Dimensioning}

Rekomendasi pemodelan jaringan EPC 4G LTE di wilayah regional Sulawesi berdasarkan hasil dimensioning dapat mengetahui jumlah element network dan bandwidth minimum yang harus di sediakan hingga tahun 2022. Hasil perancangan pemodelan umum EPC 4G LTE untuk wilayah regional Sulawesi dapat menggunakan pemodelan skenario ke dua Gambar 4.

Untuk topologi perancangan terdapat pada Gambar 5. Pemodelan skenario planning core EPC yang ke dua dapat bermanfaat untuk jangka panjang. Karena kehandalan sistemnya selain itu, cost yang dikeluarkan dari sisi pelanggan dan operator berbanding dengan efisiensi bandwidth yang disediakan.

Arsitektur jaringan EPC 4G LTE di wilayah regional Sulawesi untuk beberapa tahun kedepannya tetap menggunakan topologi full connected mesh. Pada penelitian ini untuk link transport atau media transport yang digunakan dengan menggunakan fiber optick atau serat optik. Penggunaan serat optik atau wired communication memiliki kelebihan dibandingkan dengan copper wire dan wireless transport (radio). Fiber optic selain lebih cepat dalam mentransmisikan data, sinyal loss rendah, crosstalk, bandwidth besar dan tahan terhadap interference elektro. Untuk itu sangat direkomendasikan dengan penggunaan link transport menggunakan fiber optic.

\section{Kesimpulan}

Dari hasil perhitungan dimensioning elemen jaringan untuk wilayah regional sulawesi untuk lima tahun kedepannya diperoleh 9 buah MSC Server, 2 buah HSS, 5 buah SGSN, dan 5 Buah S/PGW. Hasil perencanaan EPC 4G LTE untuk wilayah regional Sulawesi sudah sesuai dengan standar operator Telkomsel, dapat dikatakan untuk penelitian ini berhasil dilakukan.

Untuk kebutuhan bandwidth interface diperoleh untuk interface control plane terdiri dari S6a, S11, S10, S1-MME, S5/S8 sebesar 0,4015 Gbps dan kebutuhan bandwidth interface user plane terdiri dari S5/S8 user plane, S1-U dan SGi adalah 20,075 Gbps.

Media transmisi untuk implementasi sebaiknya menggunakan fiber optic yang keunggulannya mendukung kapasitas pelanggan hingga tahun 2022 dengan topologi full connection mesh dengan pooling sistem.

Untuk rekomendasi hasil perencanaan pemodelan EPC dengan menggunakan topologi planning core untuk skenario yang kedua, menguntungkan dari sisi pelanggan dan operator untuk cost berbanding dengan efisiensi bandwidth yang disediakan dan sistem yang digunakan lebih handal.

\section{Daftar Pustaka}

[1] Uke Kurniawan Usman, Galuh Prihatmoko, Denny Kusuma Hendraningrat, dan Sigit Dedi Purwanto, "Fundamental Teknologi Seluler 4G", pp 1-4. Bandung: Rekayasa Sains, 2012.

[2] Tanaka, I. Khosimizu, T. dan Nishida, K.2013.CS Fallback Function for Combined LTE and Circuit Switch (White Paper). NTT Docomo. Jepang

[3] Cox, C.2012.An Introduction to LTE, LTEadvanced, SAE, and Mobile 4G communication. United Kingdom. Wiley

[4] Mishra, ajay R.2004.Fundamentals of cellular netwrok planing \& optimization :2G,3G,3G evolution to 4G. England: John Wiley \& Sons, Ltd.

[5] Silalahi, E. 2008. Perencanaan Jaringan Inti UMTS di Bandung.Tugas Akhir. Intitut Teknologi Telkom, Bandung

[6] Septianto Bayu. Laporan Tugas Akhir Dengan Judul " 4G LTE Evolved Packet Network in Bandung", Telkom University.2015

[7] Alcatel.2010. The LTE Network Architecture (White Paper). Alcatelucent. France

[8] Nur Hasan, M. 2008 Perencanaan Core Network UMTS di Jakarta. Tugas Akhir. Institut Teknologi Telkom, Bandung

[9] Sesia, I., I. Toufik dan M.Baker.eds.2012.LTE The UMTS Long Term Evoluion From Theory to Practice. United Kingdom. Wiley 